\title{
Accuracy of electronic apex locator with different clinical conditions
}

\begin{tabular}{ccc}
\hline Nsar Muhyaddin Aziz * & Razawa Karem Saaed * & Manal Muhamad Taher * \\
\hline Abstract
\end{tabular}

Background and objective: Accuracy of working length determination is important in successful endodontic treatment. The aim of this study was to clinically compare working length determination in dry and wet canals with radiography and i- Root apex locater and in cases of presence or absence of peri apical lesion (An in vivo study).

Methods: This study was conducted in the Department of Endodontic in the College of Dentistry at Hawler Medical University, Erbil, Iraq. A total number of 45 single rooted teeth with single canals have been evaluated. An access cavity was then prepared and the pulp was extriped with barbed broach. Initial electronic measurements have been done under a wet condition; the root canals were rinsed with normal saline and then dried with paper points. i-Root TM apex locator had been used to estimate the working length. Each measurement was repeated three times and the mean value was calculated and computed. Then the K- file was selected for each tooth according to the size of each canal and peri apical radiograph had been taken to measure the length for each canal and compared with recorded length by apex locater. Statistically analysis included the used of paired sample t-test. A $P$ value of $\leq 0.05$ was considered statistically significant.

Results: There was no significant difference between working length determination by radiography and i-Root TM electronic apex locator in dry and wet canals and in case of presence or absence of peri apical lesion.

Conclusion: This study did not show any difference between radiography, i-Root TM and direct visualization in working length determination.

Keywords: Working length, i-Root TM electronic apex locator, radiography.

\section{Introduction}

The histological results after endodontic treatment have been shown by many studies to be superior when instrumentation and root filling are limited to the apical constriction which is anatomically called minor apical diameter. Therefore, accurate determination of the location of the apical constriction, (correct working length determination), is a key factor in successful root canal therapy. ${ }^{1,2}$ Root canal preparation and filling should not extend beyond the apical constriction nor leave un instrumented areas inside the root canal. The apical constriction (AC) is a logical location for working length, as it often coincides with the narrowest diameter of the root canal. ${ }^{2}$ The ideal apical endpoint of working length has been determined to be the cemento-dentinal junction. However, it is variable. On average, it occurs 0.50 to $0.75 \mathrm{~mm}$ coronal to the apical foramen, although the apical foramen occurs $0.5-\mathrm{mm}$ coronal to the anatomic Apex. ${ }^{3}$ Working length is defined as the distance from a coronal reference point to the point at which canal preparation and filling should terminate' (American Association of Endodontists). ${ }^{4}$ According to conclusions of majority of studies, the optimal rates of healing occur when instrumentation, debridement, disinfection and filling are contained within the region of apical constriction. 5 .6 Most operators attempt to determine the working length $1 \mathrm{~mm}$ short of the radiographic apex. This technique

* Department of Conservative, College of Dentistry, Hawler Medical University, Erbil, Iraq. 
works well in most cases. However, in the teeth in which the foramen is not located within the average distance from the radiographic apex, this technique will result in over- or under instrumentation of the root canal and if the major foramen deviates in the lingual or buccal plane. Radiography and electronic apex locator are two common methods for working length determination but the advantage of apex locators are that they are supposedly accurate, easy, fast and reduce exposure to radiation. ${ }^{7,8}$ An electronic method for root length determination was first investigated by Custer in 1918. The idea was revisited by Suzuki in 1942 who studied the flow of direct current through the teeth of dogs. ${ }^{8}$ Recently developed electronic apex locators (EALs) are based on the measurement of alternating current impedance. ${ }^{9}$ The development of electronic apex locators (EALs) has helped make the assessment for more accurate and predictable working length determination ${ }^{10-12}$ and if used with appropriate radiographs, it allows for much greater accuracy of working length determination. ${ }^{13,14}$ The goals of this study were to clinically compare working length determination in dry and wet canals with radiography and $i$ - Root TM apexo locater and in cases of presence and absence of peri apical lesion.

\section{Methods}

1. Selection of patients and electronic length measurement: Patients included in this study were treated at the Department of Conservative in the College of Dentistry in Hawler Medical University. All the procedures were explained for the patients and they gave their consents to the treatment. We did diagnostic peri apical radiograph for all included patient to determine the peri apical lesions. A total number of 45 single rooted teeth with single canals from 45 patients have been evaluated, $50 \%$ of patients had peri apical lesions. The teeth were anesthetized, by local anesthesia (lidocaine $2 \%$ with vasoconstrictor 1180,000 CRISTALIA, Brazilia), infiltration technique for upper teeth and block technique for lower teeth. An access cavity was prepared and the pulp was extriped with size 15 barbed broach. The root canals were flared coronally using Gates-Glidden drill No. 2 or 3 (Dentsply, Maillefer, switzerland). Initial electronic measurements have been done under a wet condition without drying of the canal. Then the root canal were rinsed with normal saline and dried with a paper point (Diadent, International, Korea) till dry paper point was obtained. i-Root TM apex locator (S-Denti, i-Root, Korea) had been used to estimate the working length in dry canals. The lip clip was attached to the patients lip, and the electrode was connected to size $15 \mathrm{~K}$-type file (Densply, Mallefer, Switzerland) with a silicone stop. The file was advanced into the canal until the display indicated the apex had been reached. The silicone stop was set on the nearest longest tip of cusp. Length was measured in millimeter to the nearest (1) millimeter. Each measurement was repeated three times and the mean value was calculated and computed. 2. Radiographic examination: After the length was determined for each canal, the K- file was selected for each tooth according to the size of each canal, then adjusted according to the average recorded reading. A per apical radiograph had been taken. The length then was measured for each canal in millimeters and was compared with recorded length by apex locater. The collected data was analyzed by using the Statistical Package for the Social Science (version 18) and Microsoft Excel, 2007 using paired sample t-test. The result was considered statistically significant when $\mathrm{P} \leq 0.05$.

\section{Results}

In this study, the accuracy of i-Root TM apex locator was compared using single canal single rooted teeth (incisor, canine and lower premolar teeth). After the measurements were completed, the values obtained were calculated using paired sample t-test to compare between 
Table 1: Difference in working length measurement by X-ray and apex locater in wet canals: paired samples t-test, descriptive statistics and ratios.

\begin{tabular}{|c|c|c|c|c|c|}
\hline Parameter & Paired Di & rences & & & \\
\hline & Mean & SD & S.E. & t-test & p value \\
\hline $\begin{array}{l}X-\text { ray and apex locater in } \\
\text { wet canals }\end{array}$ & -.08889- & .32489 & .04843 & $-1.835-$ & .173 \\
\hline
\end{tabular}

Table 2: Difference in working length determination apex locater in wet and dry canals: paired samples t-test and ratio:

Paired Differences

Mean SD S.E. t-test p value

$\begin{array}{lllllll}\begin{array}{l}\text { Apexo locater in wet and dry } \\ \text { canals }\end{array} & .03333 & .45726 & .06816 & .489 & .627\end{array}$

Table 3: Comparison between working length determination by apexo locater in case of presence or absence of peri apical lesion: paired sample t-test and ratio.

\begin{tabular}{lccccc}
\hline Parameter & \multicolumn{2}{c}{ Paired Differences } & & \\
& Mean & SD & S.E. & t-test & p value \\
\hline $\begin{array}{l}\text { Apex locater in present and } \\
\text { absence of pri apical lesion }\end{array}$ & $-.08889-$ & .47194 & .07035 & $-.948-$ & .349 \\
\hline
\end{tabular}

measurement obtained by apex locater in wet canals and measurement obtained by X-ray. The findings showed that there was no significant difference between the two methods $(P=0.173)$ (Table 1$)$. As shown in Table 2 there was no significant difference between working length measurement by apex locater in dry and wet canals by using paired sample t-test $(P>0.05)$. The absolute measurement of the two methods were compared using paired sample t-test, exhibiting no statistically significant differences in measurement between the two methods $(P>0.05)$. There was no statistically significant difference between the dry and wet canals when measuring by paired sample t-test (Table 2). We also found that there was no statistically significant difference between the presence and absence of peri apical lesions in working length determination by apex locater in both case of dry and wet canals (Table 3 ).

\section{Discussion}

The use of electronic devices to determine working length has gained increasing popularity in recent years. ${ }^{15}$ Modern apex locators are able to determine an area between the minor and major apical foramina by measuring the impedance between the file tip and the canal with different frequencies and enables tooth length measurements in the presence of electrical conductive media in the root canals. ${ }^{16}$ Although we have more accurate type of EAL, in our study we selected the i-Root EAL because of its simplicity. 
In our study we concluded that there was no significant difference between working length determination during root canal treatment by radiograph and EAL (i-Root). This non-significant difference may be due to change in instrument position ( $\mathrm{K}$ file) inside the canal during taking $\mathrm{X}$-ray or during reading the working length by $E A L$, so by taking the instruments slightly long when using EALs and then retracting them may increase the accuracy of readings of EALs. ${ }^{17,18}$ However, Guise et al suggested subtraction of $0.5 \mathrm{~mm}$ from the measured length results in overextended preparation in some instances. In present study we also concluded that the conditions of the canals (dry and wet canals) did not affect the working length determination by EAL. This non significant difference may be due to EAL precise, therefore, to determine the minor constriction it is better to subtract 1 $\mathrm{mm}$ from the electronic readings of the apical foramen. ${ }^{19}$ In our study, in presence and absence of peri apical lesion there was no significant difference in working length determination either by EAL or by $x$-ray. Nguyen et $\mathrm{al}^{20}$ showed that electronic working length determination is not influenced by size of file used, so in present study a size of $15 \mathrm{k}$-file was used in all cases. The results of the present study confirmed that EALs can accurately determine the canal length within $\pm 0.5 \mathrm{~mm}$ from the apical constriction in both wet and dry canal and the result of this study was agreed with Kauffman et al and Plotino et al. ${ }^{21,22}$ Radiographic determination of working length has been used for many years. The radiographic apex is defined as the anatomical end of the root as seen on the radiograph, while the apical foramen is the region where the canal leaves the root surface next to the periodontal ligament. ${ }^{22}$ The results of this study from radiography and EAL were similar showing that each of the two radiography and EAL methods are reliable and there is no need to use them together. This result was agreed with Zand et al. ${ }^{23}$

\section{Conclusion}

This study did not show any significant differences between working length determination by radiography which was used as a control group and apex locater. It also did not show any significant differences between dry and wet canal by apex locater. Presence and absence of peri apical lesion did not have any significant effect on working length determination, although, further studies are necessary.

\section{Conflicts of interest}

The authors report no conflicts of interest.

\section{References}

1. Ricucci D, Langeland K. Apical limit of root canal instrumentation and obturation, part 2. A histological study. Int Endod J1998; 31: 394-409.

2. Vieyra JP, Acosta J, Mondaca JM. Comparison of working length determination with radiographs and two electronic apex locators. Int Endod $\mathrm{J}$ 2010; 43(1):16-20.

3. Assunção DF, Albuquerque D, Ferreira D. The Ability of two apex locators to locate the apical foramen: An In Vitro Study. J Endod 2006; 32:6.

4. American Association of Endodontists (AAE). Glossary of Endodontic Terms; 7th edn. Chicago, IL: American Association of Endodontists; 2003.

5. Basmadjian-Charles CL, Farge P, Bourgeois DM, Lebrun $T$. Factors influencing the long-term results of endodontic treatment: $A$ review of the literature. Int Dent J 2002; 52:81-6.

6. Kojima K, Inamoto K, Nagamatsu K. Success rate of endodontic treatment of teeth with vital and nonvitalpulps. A meta-analysis. J Endod 2004; 97:95-9.

7. Gordon MP, Chandler NP. Electronic apex locators. Int Endod J 2004; 37:425-37.

8. Sharma C, Arora M. Determination of Working Length of Root Canal. MJAFI 2010; 66(3):231-4.

9. Schaeffer MA, White RR, Walton RE. Determining the optimal obturation length: A meta-analysis of literature. J Endod 2005; 31:271- 4.

10. Suzuki K. Experimental study on iontophoresis. Jap J of Stomat 1942; 16:411-29.

11. Nekoofar MH, Ghandi MM, Hayes SJ, Dummer $\mathrm{PMH}$. The fundamental operating principles of electronic root canal length measurement devices. Int Endod J 2006; 39:595-609.

12. Pratten D, McDonald NJ. Comparison of radiographic and electronic working lengths. J Endod 1996; 22:173-6.

13. Fouad AF, Reid LC. Effect of using electronic apex locators on selected endodontic treatment parameters. J Endod 2000; 26:364-7. 
14. ElAyouti A, Weiger $R$, Lost $C$. The ability of root ZX apex locator to reduce the frequency of overestimated radiographic working length. J Endod 2002; 28:116-9.

15. Hoer D, Attin T. The accuracy of electronic working length determination. Int Endod J 2004; 37:125-31.

16. Kim E, Lee SJ. Electronic apex locator. Dent Clin North Am 2004; 48(1):35-54.

17. Dunlap CA, Remeikis NA, BeGole EA, Rauschenberger $C R$. An in vivo evaluation of an electronic apex locator that uses the ratio method in vital and necrotic canals. J Endod 1998; 24:48-50.

18. Lee SJ, Nam KC, Kim YJ, Kim DW. Clinical accuracy of a new apex locator with an autmatic compensation circuit. J Endod 2002; 28: 706-9.

19. Guise GM, Goodel GG, Imamura GM. In vitro comparison of three electronic apex locators. J Endod 2010; 36:279-81.

20. Nguyen $H$, Kaufman A, Komorowski R, Friedman $\mathrm{S}$. Electronic length measurement using small and large files in enlarged canals. Int Endod $\mathrm{J}$ 1996; 29:359-64.

21. Kauffman AY, Keila S, Yoshpe M. Accuracy of a new apex locator: an in vitro study. Int Endod J 2002; 35:186-92.

22. Plotino G, Grande N, Brigante L, Lesti B, Somma F. Ex vivo accuracy of three electronic apex locators: Root ZX, Elements Diagnostic Unit and Apex Locator and ProPex. Int Endod J 2005; 39:408-14.

23. Zand V, Mokhtari $H$, Lotfi M, Reyhani $M$, Sohrab A, Tehranchi P. Accuracy of working length determination with root ZX apex locator and radiography: $A n$ in vivo and ex vivo study. Afr J Biotechnol 2011; 10(36):7088-91. 